\title{
PERCEPÇÕES DE COOPERADOS E NÃO COOPERADOS EM RELAÇÃO À DIMENSÃO SOCIAL DA SUSTENTABILIDADE DE UMA COOPERATIVA LEITEIRA DA AGRICULTURA FAMILIAR
}

\begin{abstract}
PERCEPTIONS OF COOPERATED AND NON-COOPERATED IN RELATION TO THE SOCIAL DIMENSION OF SUSTAINABILITY OF A DAIRY COOPERATIVE IN FAMILY AGRICULTURE
\end{abstract}

\section{Evandro Tiozo}

evandrotiozo@gmail.com

Universidade Estadual do Oeste do Paraná - Cascavel/Paraná, Brasil

https://orcid.org/0000-0002-5394-0544

\section{Geysler Rogis Flor Bertolini}

geysler rogis@yahoo.com.br

Universidade Estadual do Oeste do Paraná - Cascavel/Paraná, Brasil

https://orcid.org/0000-0001-9424-4089

\begin{abstract}
Resumo
O presente estudo teve como objetivo investigar se ser cooperado ou não em uma cooperativa leiteira influencia na dimensão social da sustentabilidade da agricultura familiar. As análises foram realizadas pela Modelagem de Equações Estruturais, com estimação dos "Mínimos Quadrados Parciais", utilizando o software SmartPLS ${ }^{\circledR}$ 3.0, com a validação dos constructos e o teste de hipóteses. Verificou-se que a cooperativa influencia positivamente na dimensão social da sustentabilidade dos cooperados, pois as percepções dos cooperados foram positivas e significativas estatisticamente quando comparadas com as opiniões dos não cooperados, demonstrando que ser cooperado impacta positivamente nesta relação entre cooperativa e agricultura familiar.
\end{abstract}

Palavras-chave: Sustentabilidade. Pequeno produtor. Cooperativismo. Dimensão social.

\begin{abstract}
The present study aimed to investigate whether or not being cooperated in a dairy cooperative influences the social dimension of the sustainability of family farming. The analyzes were performed by Structural Equation Modeling, with estimation of "Partial Least Squares", using the SmartPLS ${ }^{\circ} 3.0$ software, with construct validation and hypothesis testing. It was found that the cooperative positively influences the social dimension of the sustainability of the cooperative members, as the perceptions of the cooperative members were positive and statistically significant when compared with the opinions of the noncooperatives, demonstrating that being a member of the cooperative positively impacts this relationship between cooperatives and family farming.
\end{abstract}

Keywords: Sustainability. Small producer. Cooperativism. Social dimension. 


\section{Introdução}

A agricultura tem grande representatividade no país, e segue avançando, adotando práticas que visam o desenvolvimento sustentável, no entanto, ainda se nota a insustentabilidade presente nesse setor, principalmente para os pequenos agricultores, onde se verifica que muitos estudos vêm apontando essa questão, permitindo a possibilidade de novos incentivos, por parte de políticas públicas principalmente, para o desenvolvimento de práticas sustentáveis pelos produtores (Zanella \& Lago, 2017).

A agricultura tem alto impacto na sustentabilidade não só dela, mas da população como um todo, pois seu alto nível de detenção de terras produtivas e sua interação direta com elas faz com que ela contribua com problemas que afetam os ecossistemas globais, como a escassez de água, a sobrecarga de nutrientes, mudanças climáticas, mudança nos habitats e a perda da biodiversidade (Tilman, Cassman, Matson, Naylor, \& Polasky, 2002). Assim, a crescente necessidade de aumento da produtividade dos agrossistemas impacta consequentemente em acelerada degradação dos ecossistemas (Davari, Ram, Tewari, \& Kaushish, 2010; Esteves Neto, 2014).

A agricultura é de suma importância para a sociedade, pois além de fornecer alimentos, sendo responsável por $70 \%$ dos alimentos consumidos pelos brasileiros (Portal Brasil, 2015), ainda será a forma como ela trabalha que definirá como o planeta se moldará para o futuro, pois a demanda global de alimentos vem crescendo rapidamente, representando enormes desafios para a sustentabilidade, e com isso tem-se que os agricultores são os principais detentores de terras utilizáveis globais, e eles moldarão, talvez irreversivelmente, a superfície da terra nas próximas décadas, então vê-se como crucial a ação para que esta situação se torne sustentável, com novos incentivos e políticas para assegurar a sustentabilidade da agricultura, e consequentemente dos ecossistemas do qual a população mundial faz parte (Tilman et al., 2002).

Os estudos demonstram que os agricultores familiares têm um bom grau de conhecimento sobre as práticas sustentáveis, embora não seja a maior parte que desenvolve seus trabalhos dessa forma, sendo possível observar que ainda há um longo caminho a percorrer para se chegar ao desenvolvimento sustentável na agricultura familiar (Riedner, Bertolini, Ribeiro, \& Brandalise, 2018).

A mudança da agricultura familiar tradicional para a agricultura familiar sustentável pode ser apoiada com uma visão melhorada dos sistemas agrícolas já existentes, ou seja, para tornar-se sustentável não são todos os casos que necessitam de investimentos tecnológicos, apenas a mudança de hábito e formas de produção pode fazer com que o sistema seja sustentável (Ssebunya et al., 2019).

Com o apresentado verifica-se a importância da sustentabilidade para a agricultura familiar, sendo importante então entender do que se trata a sustentabilidade, e um conceito de desenvolvimento sustentável, apresentado do relatório de Brundtland em 1987, define de forma clara e objetiva o termo, que pode ser entendido como "o desenvolvimento que satisfaz as necessidades presentes, sem comprometer a capacidade das gerações futuras de suprir suas próprias necessidades" (Brundtland, Khalid, Agnelli, \& Al-Athel, 1987).

Compreendido o conceito do termo, tem-se também que a sustentabilidade pode ser entendida como uma junção de dimensões, que conforme Elkington (1998), envolve três dimensões, que são elas, econômica, social e ambiental, formando assim o termo definido por ele como The Triple Bottom Line, conhecido como tripé da sustentabilidade. Nesse sentido, as cooperativas têm desempenhado a importante função de melhorar e equilibrar essas três dimensões da sustentabilidade para a agricultura familiar (Giagnocavo, Galdeano-Gómez, \& Pérez-Mesa, 2018).

As cooperativas assumem importante papel na sustentabilidade da agricultura familiar, pois propiciam à agricultura familiar maior competitividade com o mercado, ampliando suas redes de mercado e políticas 
públicas, tornando-as mais rentáveis, favorecendo o seu desenvolvimento, destarte, lhe elevando a um maior nível de sustentabilidade (Freitag, Klesener, \& Plein, 2019).

Em sua longa trajetória de existência a atividade agrícola teve grandes evoluções até chegar ao nível em que se encontra hoje. Com a sua evolução, principalmente a tecnológica, resultou em aumento produtivo, melhorando seus aspectos econômicos, no entanto, ao melhorar algumas dimensões outras acabaram indo no sentido inverso, como a questão social, pois algumas práticas prejudicam-na diretamente, como exemplo o fato dos indivíduos ficarem mais isolados, trocando o contato com pessoas por máquinas (Assad \& Almeida, 2004).

A sustentabilidade, em suas dimensões, pode ser observada de forma individual em cada uma delas, em que cada uma tem suas próprias particularidades e contribuições, desta forma tem-se três sustentabilidades, a econômica, social e ambiental (Munck, Bansi, Dias, \& Cella-de-Oliveira, 2013).

Com a situação apresentada, identificada a importância da dimensão social, entende-se que esta é um importante pilar da sustentabilidade e que está interligada com as dimensões econômica e ambiental, às impactando, pois como Galdeano-Gómez, Aznar-Sánchez, Pérez-Mesa e Piedra-Muñoz (2017) identificaram, o aumento nos indicadores econômicos e sociais reduzem as pressões ambientais sobre o uso de recursos, e paralelamente, pode-se observar também que melhorias sociais e ambientais revelam efeitos positivos na dimensão econômica dos agricultores.

Analisando a abordagem sobre o tema, verificou-se que que embora os 50 trabalhos estudados abordem a questão do papel das cooperativas para a dimensão social sustentabilidade da agricultura familiar, em nenhum deles realmente foi abordado o impacto do papel das cooperativas para esse nível de sustentabilidade, o que não demonstra realmente que o nível de sustentabilidade encontrado é devido as ações das cooperativas para com a agricultura familiar como um todo e para os cooperados, o que não indica que uma cooperativa teve real impacto sobre a sustentabilidade na dimensão social dos agricultores familiares, podendo ser diferente ou igual dos cooperados e dos não cooperados. Dos trabalhos analisados, tem-se as dissertações de Miranda (2008), Pereira (2008), Gotuzzo (2009), Santos (2010), Francio (2011), Garcia (2011), Raupp (2012), Gonçalves da Silva (2013), Pedon (2013), Ternoski (2013), Tokarski (2013), Silva (2013), Xavier (2013), Hahn (2014), Valandro (2014), Vendrame (2014), Kunzler (2015), Nascimento (2015), Paetzold (2015), Rodrigues (2015), Bangel (2017) e Guedes (2018).

Seguindo quanto aos estudos analisados, tem-se as teses de Binda (2014) e Mallmann (2017) e os artigos de Ignácio e Souza (2008), Marschall (2009), Alves, Vieira, Silva e Ferreira (2011), Freitas, Amodeo e Silva (2012), Andersson, Mauch e Bezerra (2012), Andrade e Alves (2013), Dias, Nunes, Torres e Torres (2013), Freitas e Freitas (2013), Santos e Cândido (2013), Silva, Barbosa e Albuquerque (2013), Winck, Zonin, Scarton e Silva (2014), Arruda, Matos, Machado e Arruda (2015), Simioni, Binotto e Battiston (2015), Boessio e Doula (2016), Dávila e Molina (2016), Melz e Sehnem (2016), Tenzin e Natsuda (2016), Breitenbach, Brandão e Zorzan (2017), Drebes e Spanevello (2017), Kunzler e Badalotti (2017), Santos, Rodrigues e Medina (2017), Casagrande e Begnini (2018), Ferreira, Von Ende, Rossés e Neumann (2018), Pires e Hoff (2018), Santos (2018) e Santos, Campos, Ferreira e Freitas (2018), destes trabalhos embora não realizem uma comparação entre cooperados e não cooperados, eles contribuem fornecendo informações importantes quanto às contribuições das cooperativas para a dimensão social da sustentabilidade da agricultura familiar.

Com a literatura apresentada e verificando a existência da lacuna, cabe uma melhor compreensão sobre a influência que uma cooperativa pode exercer sobre a sustentabilidade na dimensão social da agricultura familiar, verificando se impactam de forma diferente os cooperados e os não cooperados, já que quando os autores apresentam que as cooperativas contribuem para a agricultura familiar, seria interessante verificar se na percepção dos agricultores familiares que não são cooperados essas contribuições são visualizadas da mesma forma que para os cooperados. Desta forma a presente pesquisa tem como 
objetivo: investigar se o fato de ser cooperado ou não em uma cooperativa leiteira influencia na dimensão social da sustentabilidade da agricultura familiar.

\section{Desenvolvimento teórico}

Neste capítulo são apresentadas as teorias que deram base para o desenvolvimento deste estudo, sendo dividido em dois subcapítulos. Primeiramente será abordada a dimensão social da sustentabilidade, e na sequência serão apresentados os estudos similares, juntamente com a formulação das hipóteses de pesquisa, sendo geradas a partir dos constructos que envolvem a dimensão social da sustentabilidade.

\section{Dimensão social da sustentabilidade}

Na presente seção é apresentada a dimensão social da sustentabilidade, com base em autores relevantes sobre o tema, possibilitando maior entendimento sobre a forma com a qual se trabalha o tema da sustentabilidade quanto à sua dimensão social.

Sachs (2008) define a dimensão social em um contexto global, não apenas empresarial, sendo conceituada como uma homogeneidade social e melhoria na qualidade de vida, com distribuições mais justas, como a distribuição da renda, oportunidades de emprego e melhoria no acesso aos recursos e serviços sociais.

Na percepção de Barbieri et al. (2010), abordando a dimensão social mais voltada ao meio corporativo, ela pode ser entendida como a preocupação com os impactos sociais das atividades nas comunidades humanas dentro e fora da organização.

Complementando as percepções destes autores, Werbach (2010), define a dimensão social como sendo necessário considerar os outros indivíduos em suas ações, favorecendo e propiciando melhoria nas condições de vida para todos os membros da sociedade, auxiliando no combate à pobreza, violência e injustiça, e contribuindo para melhoria na educação, saúde, trabalho e direitos humanos.

Com as definições descritas tem-se uma ideia do que se contempla na dimensão social que será utilizada no desenvolvimento do presente estudo. Relacionando a sustentabilidade social com as cooperativas temse que a característica social é um forte pilar que une a agricultura familiar com as cooperativas, pois mesmo que economicamente as cooperativas algumas vezes apresentem valores menos atrativos que o mercado, o agricultor encontra na cooperativa uma relação mais forte e duradoura, considerando-a uma ajuda mútua, evidenciando o quão importante é a dimensão social na sustentabilidade da agricultura familiar (Azevedo, 2013).

As cooperativas são entendidas como facilitadoras das práticas sustentáveis sociais para a agricultura familiar, pois elas fornecem suporte e conhecimentos que os cooperados possivelmente não teriam acesso caso não tivessem o apoio da cooperativa, desta forma, ela pode ser entendida como peça fundamental, sendo uma ponte entre a agricultura familiar e a sustentabilidade (Silva \& Torres, 2020).

Abordada a dimensão social da sustentabilidade, na sequência inicia-se a abordagem dos estudos semelhantes, os quais forneceram suporte para o desenvolvimento das hipóteses de pesquisa.

\section{Estudos similares}

Neste tópico são apresentados os estudos relacionados ao tema da presente pesquisa, os quais, conforme salientado na introdução desta pesquisa, embora analisem a sustentabilidade proporcionada pelas cooperativas para a agricultura familiar, não realizaram uma comparação entre os cooperados e não cooperados para verificar de fato se essas contribuições são significantes em relação à sustentabilidade dos cooperados, possibilitando que estes tenham um nível maior de sustentabilidade em decorrência disso. 
Para este capítulo considerou-se relevante verificar, com base nos trabalhos relacionados, quais as contribuições que as cooperativas proporcionam para uma maior sustentabilidade social da agricultura familiar. É relevante argumentar que para melhor apresentação destas variáveis, realizou-se uma divisão em constructos, relacionando as questões em que cada uma delas está relacionada.

Como este capítulo descreve informações de estudos semelhantes, considerou-se propício formular as hipóteses a partir destas teorias, assim, após cada constructo será apresentada uma hipótese.

Quanto aos constructos formulados, é importante salientar que, foram levantadas todas as variáveis sociais identificadas na literatura, sendo elas aplicadas para a cooperativa foco da pesquisa ou não, as quais serão validadas no Capítulo "Apresentação e análise dos resultados", já que desta forma, com todas as variáveis identificadas na teoria sendo apresentadas, torna o trabalho replicável e adaptável para outras cooperativas.

Na Figura 1 é apresentado um modelo demonstrando os quatro constructos formulados a partir da dimensão social, os quais envolveram as contribuições das cooperativas para a sustentabilidade social da agricultura familiar.

Para nomeação dos constructos sociais, tomou-se como base as variáveis identificadas na literatura, unindo as que tivessem maior relação quanto às contribuições das cooperativas, e nomeando o constructo de acordo com a característica mais presente nestas variáveis, onde o constructo Envolvimento relaciona as variáveis que demonstram uma relação mais próxima entre os agricultores familiares, o Fortalecimento implica em aspectos que insinuam ações que dão força para que os pequenos produtores permaneçam ativos, já o conhecimento relaciona questões na qual são demonstradas ações que de alguma forma ensinam os cooperados, e a Comercialização engloba aspectos que envolvem a venda de forma justa, em que os agricultores se ajudam mutuamente nesta relação de venda.

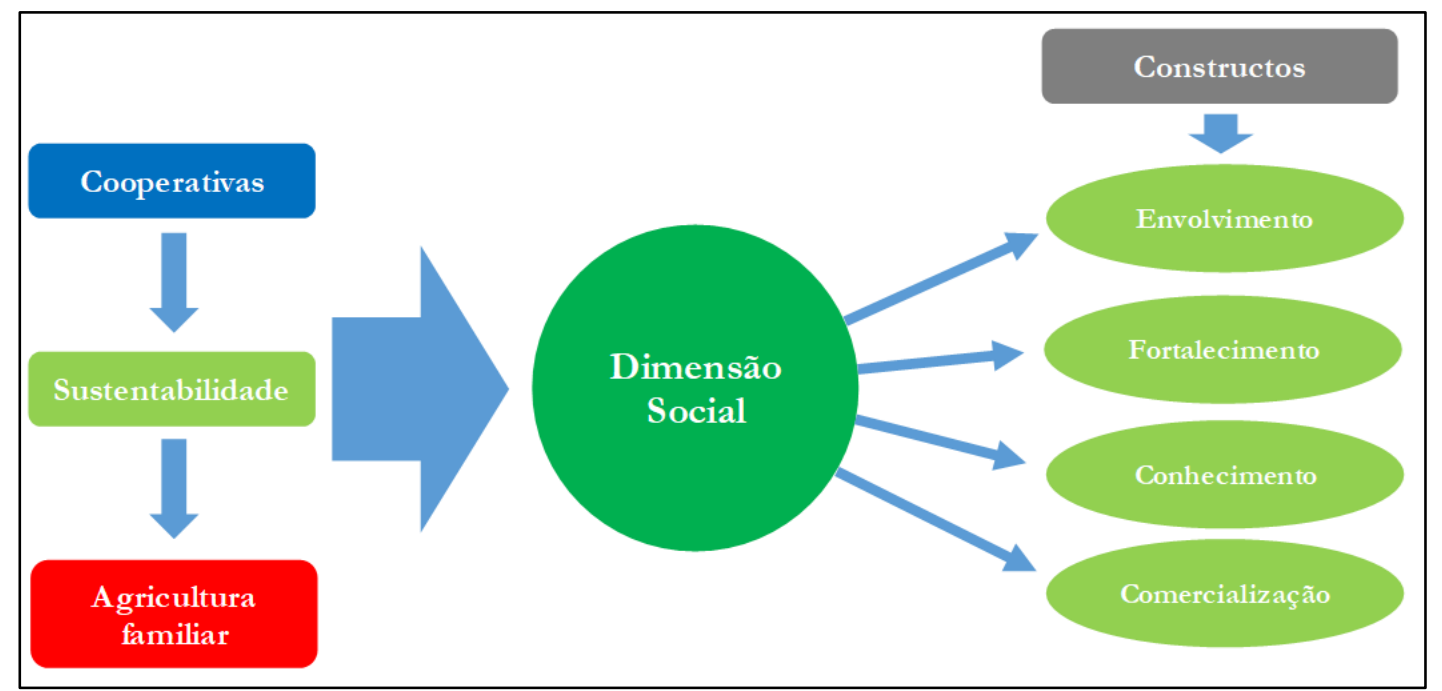

Figura 1. Constructos da dimensão social da sustentabilidade proporcionada pelas cooperativas para a agricultura familiar Fonte: Dados da pesquisa (2020)

Visualizados os quatro constructos da dimensão social conforme a Figura 1, das figuras 2 até a 5, demonstram-se as variáveis da dimensão social da sustentabilidade, e serão apresentados na seguinte sequência: Envolvimento (Figura 2), Fortalecimento (Figura 3), Conhecimento (Figura 4) e Comercialização (Figura 5). 


\begin{tabular}{|c|c|}
\hline Variáveis & Referências \\
\hline $\begin{array}{l}\text { As cooperativas contribuem } \\
\text { para um maior } \\
\text { envolvimento social entre os } \\
\text { cooperados }\end{array}$ & $\begin{array}{l}\text { Ignácio e Souza (2008), Miranda (2008), Pereira (2008), Gotuzzo (2009), Marschall (2009), } \\
\text { Santos (2010), Alves et al. (2011), Francio (2011), Garcia (2011), Andersson, Mauch e Bezerra } \\
\text { (2012), Freitas, Amodeo e Silva (2012), Raupp (2012), Freitas e Freitas (2013), Gonçalves da } \\
\text { Silva (2013), Pedon (2013), Santos e Cândido (2013), Silva (2013), Silva, Barbosa e } \\
\text { Albuquerque (2013), Ternoski (2013), Tokarski (2013), Xavier (2013), Binda (2014), Hahn } \\
\text { (2014), Valandro (2014), Vendrame (2014), Arruda et al. (2015), Kunzler (2015), } \\
\text { Nascimento (2015), Rodrigues (2015), Simioni, Binotto e Battiston (2015), Boessio e Doula } \\
\text { (2016), Davila e Molina (2016), Tenzin e Natsuda (2016), Bangel (2017), Breitenbach, } \\
\text { Brandão e Zorzan (2017), Drebes e Spanevello (2017), Kunzler e Badalotti (2017), } \\
\text { Mallmann (2017), Santos, Rodrigues e Medina (2017), Casagrande e Begnini (2018), Ferreira } \\
\text { et al. (2018), Guedes (2018), Pires e Hoff (2018) e Santos (2018) }\end{array}$ \\
\hline $\begin{array}{c}\text { As cooperativas contribuem } \\
\text { para a solidariedade entre os } \\
\text { cooperados }\end{array}$ & $\begin{array}{l}\text { Ignácio e Souza (2008), Gotuzzo (2009), Marschall (2009), Santos (2010), Alves et al. (2011), } \\
\text { Francio (2011), Andersson, Mauch e Bezerra (2012), Freitas, Amodeo e Silva (2012), Raupp } \\
\text { (2012), Freitas e Freitas (2013), Gonçalves da Silva (2013), Santos e Cândido (2013), Silva } \\
\text { (2013), Silva, Barbosa e Albuquerque (2013), Tokarski (2013), Xavier (2013), Binda (2014), } \\
\text { Hahn (2014), Vendrame (2014), Arruda et al. (2015), Kunzler (2015), Boessio e Doula } \\
\text { (2016), Davila e Molina (2016), Tenzin e Natsuda (2016), Kunzler e Badalotti (2017), } \\
\text { Mallmann (2017), Casagrande e Begnini (2018) e Pires e Hoff (2018) }\end{array}$ \\
\hline $\begin{array}{c}\text { As cooperativas envolvem } \\
\text { os cooperados na tomada } \\
\text { de decisão }\end{array}$ & $\begin{array}{l}\text { Ignádio e Souza (2008), Gotuzzo (2009), Marschall (2009), Santos (2010), Andersson, } \\
\text { Mauch e Bezerra (2012), Freitas, Amodeo e Silva (2012), Freitas e Freitas (2013), Silva (2013), } \\
\text { Silva, Barbosa e Albuquerque (2013), Xavier (2013), Binda (2014), Hahn (2014), Arruda et al. } \\
\text { (2015), Nascimento (2015), Rodrigues (2015), Davila e Molina (2016), Casagrande e Begnini } \\
\text { (2018) e Guedes (2018) }\end{array}$ \\
\hline $\begin{array}{l}\text { As cooperativas incentivam } \\
\text { que o jovem continue no } \\
\text { campo, colaborando para a } \\
\text { sucessão familiar }\end{array}$ & $\begin{array}{l}\text { Freitas e Freitas (2013), Xavier (2013), Binda (2014), Boessio e Doula (2016), Bangel (2017) e } \\
\text { Drebes e Spanevello (2017) }\end{array}$ \\
\hline $\begin{array}{l}\text { As cooperativas propiciam } \\
\text { aos cooperados maior nível } \\
\text { de sentimento de pertença } \\
\text { ao grupo }\end{array}$ & $\begin{array}{c}\text { Gotuzzo (2009), Marschall (2009), Silva, Barbosa e Albuquerque (2013), Simioni, Binotto e } \\
\text { Battiston (2015), Davila e Molina (2016) e Pires e Hoff (2018) }\end{array}$ \\
\hline $\begin{array}{c}\text { As cooperativas propiciam } \\
\text { aos cooperados maior nível } \\
\text { de sentimento de pertença } \\
\text { ao local em que vivem }\end{array}$ & Marschall (2009), Pires e Hoff (2018) e Santos (2018) \\
\hline $\begin{array}{l}\text { As cooperativas buscam pela } \\
\text { equidade de gênero na } \\
\text { participação nas } \\
\text { cooperativas, incentivando a } \\
\text { participação de mulheres }\end{array}$ & Xavier (2013) e Binda (2014) \\
\hline
\end{tabular}

Figura 2. Variáveis do constructo Envolvimento da dimensão social da sustentabilidade

Fonte: Dados da pesquisa (2020)

$\mathrm{Na}$ Figura 2, verifica-se que as cooperativas contribuem para a o envolvimento social e solidariedade entre os cooperados, os envolvendo na tomada de decisão, além de ter um importante papel na sucessão familiar e trazendo à tona a importância de buscar a equidade de gênero em suas atividades, com isso, consegue transmitir significado a participação dos agricultores familiares, fazendo com que se sintam mais pertencentes ao grupo e ao local em que vivem (Guedes, 2018; Pires \& Hoff, 2018; Santos, 2018). A partir disto é formulada a primeira hipótese da dimensão social.

Hipótese 1 (H1): a cooperativa influencia positivamente no envolvimento na dimensão social da sustentabilidade dos cooperados da agricultura familiar. 
Apresentada a primeira hipótese do estudo, continuando com a dimensão social, na Figura 3 apresentamse as variáveis do constructo Fortalecimento da dimensão social da sustentabilidade proporcionada pelas cooperativas para a agricultura familiar.

\begin{tabular}{|c|c|}
\hline Variáveis & Referências \\
\hline $\begin{array}{l}\text { As cooperativas contribuem } \\
\text { para o desenvolvimento } \\
\text { local e regional }\end{array}$ & $\begin{array}{l}\text { Ignádio e Souza (2008), Pereira (2008), Marschall (2009), Santos (2010), Alves et al. (2011), } \\
\text { Francio (2011), Garcia (2011), Andersson, Mauch e Bezerra (2012), Freitas, Amodeo e Silva } \\
\text { (2012), Raupp (2012), Andrade e Alves (2013), Freitas e Freitas (2013), Santos e Cândido } \\
\text { (2013), Silva, Barbosa e Albuquerque (2013), Tokarski (2013), Xavier (2013), Binda (2014), } \\
\text { Hahn (2014), Vendrame (2014), Winck et al. (2014), Kunzler (2015), Davila e Molina (2016), } \\
\text { Tenzin e Natsuda (2016), Kunzler e Badalotti (2017), Santos, Rodrigues e Medina (2017), } \\
\text { Casagrande e Begnini (2018), Ferreira et al. (2018), Pires e Hoff (2018) e Santos (2018) }\end{array}$ \\
\hline $\begin{array}{l}\text { As cooperativas contribuem } \\
\text { para o combate da pobreza } \\
\text { da agricultura familiar }\end{array}$ & $\begin{array}{l}\text { Gotuzzo (2009), Santos (2010), Alves et al. (2011), Francio (2011), Garcia (2011), Freitas, } \\
\text { Amodeo e Silva (2012), Pedon (2013), Silva (2013), Tokarski (2013), Binda (2014), Hahn } \\
\text { (2014), Davila e Molina (2016), Santos, Rodrigues e Medina (2017) e Guedes (2018) }\end{array}$ \\
\hline $\begin{array}{c}\text { As cooperativas fortalecem a } \\
\text { agricultura familiar }\end{array}$ & $\begin{array}{l}\text { Pereira (2008), Gotuzzo (2009), Santos (2010), Francio (2011), Garcia (2011), Freitas, } \\
\text { Amodeo e Silva (2012), Raupp (2012), Andrade e Alves (2013), Freitas e Freitas (2013), } \\
\text { Gonçalves da Silva (2013), Pedon (2013), Silva, Barbosa e Albuquerque (2013), Tokarski } \\
\text { (2013), Silva (2013), Xavier (2013), Binda (2014), Hahn (2014), Vendrame (2014), Kunzler } \\
\text { (2015), Rodrigues (2015), Davila e Molina (2016), Tenzin e Natsuda (2016), Bangel (2017), } \\
\text { Drebes e Spanevello (2017), Kunzler e Badalotti (2017), Mallmann (2017), Ferreira et al. } \\
\text { (2018), Guedes (2018), Pires e Hoff (2018) e Santos (2018) }\end{array}$ \\
\hline $\begin{array}{l}\text { As cooperativas contribuem } \\
\text { para o surgimento e } \\
\text { expansão de novos } \\
\text { empreendimentos }\end{array}$ & $\begin{array}{c}\text { Pereira (2008), Gotuzzo (2009), Santos (2010), Alves et al. (2011), Andersson, Mauch e } \\
\text { Bezerra (2012), Freitas, Amodeo e Silva (2012), Freitas e Freitas (2013), Binda (2014) e } \\
\text { Vendrame (2014) }\end{array}$ \\
\hline $\begin{array}{l}\text { As cooperativas melhoram a } \\
\text { qualidade de vida da } \\
\text { agricultura familiar }\end{array}$ & $\begin{array}{l}\text { Miranda (2008), Pereira (2008), Gotuzzo (2009), Santos (2010), Francio (2011), Gardia } \\
\text { (2011), Andersson, Mauch e Bezerra (2012), Freitas, Amodeo e Silva (2012), Andrade e Alves } \\
\text { (2013), Pedon (2013), Silva (2013), Tokarski (2013), Xavier (2013), Binda (2014), Hahn } \\
\text { (2014), Vendrame (2014), Davila e Molina (2016), Bangel (2017), Mallmann (2017), Santos, } \\
\text { Rodrigues e Medina (2017), Ferreira et al. (2018) e Guedes (2018) }\end{array}$ \\
\hline $\begin{array}{l}\text { As cooperativas auxiliam na } \\
\text { sobrevivência das culturas de } \\
\text { pequena propriedade }\end{array}$ & $\begin{array}{c}\text { Marschall (2009), Santos (2010), Francio (2011), Andersson, Mauch e Bezerra (2012), Silva, } \\
\text { Barbosa e Albuquerque (2013), Tokarski (2013), Binda (2014), Hahn (2014), Vendrame } \\
\text { (2014), Kunzler (2015), Davila e Molina (2016), Kunzler e Badalotti (2017), Ferreira et al. } \\
\text { (2018) e Santos (2018) }\end{array}$ \\
\hline
\end{tabular}

Figura 3. Variáveis do constructo Fortalecimento da dimensão social da sustentabilidade

Fonte: Dados da pesquisa (2020)

Sobre o constructo Fortalecimento, na Figura 3, é possível identificar que as cooperativas contribuem para o desenvolvimento local e regional, com o surgimento e expansão de novos empreendimentos sendo impactados pelas suas atividades, além de combater a pobreza e auxiliar na sobrevivência das culturas de pequena propriedade da agricultura familiar, melhorando a qualidade de vida e à fortalecendo (Vendrame, 2014; Santos, Rodrigues, \& Medina, 2017; Ferreira et al., 2018). Com o apresentado chega-se a segunda hipótese.

Hipótese 2 (H2): a cooperativa influencia positivamente no fortalecimento na dimensão social da sustentabilidade dos cooperados da agricultura familiar.

Com a segunda hipótese da dimensão social formulada, na Figura 4 são demonstradas as variáveis do constructo Conhecimento da dimensão social da sustentabilidade proporcionada pelas cooperativas para a agricultura familiar. 


\begin{tabular}{|c|c|c|}
\hline Variáveis & Referências \\
\hline $\begin{array}{c}\text { As cooperativas oferecem } \\
\text { aursos para capacitaça da } \\
\text { agricultura familiar }\end{array}$ & $\begin{array}{c}\text { Ignácio e Souza (2008), Pereira (2008), Marschall (2009), Francio (2011), Freitas, Amodeo e } \\
\text { Silva (2012), Pedon (2013), Xavier (2013), Binda (2014), Valandro (2014), Vendrame (2014), } \\
\text { Simioni, Binotto e Battiston (2015), Boessio e Doula (2016), Davila e Molina (2016), Bangel } \\
\text { (2017), Breitenbach, Brandão e Zorzan (2017), Drebes e Spanevello (2017), Mallmann } \\
\text { (2017), Pires e Hoff (2018) e Santos (2018) }\end{array}$ \\
\hline $\begin{array}{c}\text { As cooperativas incentivam } \\
\text { a busca de conhecimento } \\
\text { por parte dos cooperados }\end{array}$ & $\begin{array}{c}\text { Ignácio e Souza (2008), Marschall (2009), Santos (2010), Andrade e Alves (2013), Arruda et } \\
\text { al. (2015), Simioni, Binotto e Battiston (2015), Boessio e Doula (2016), Melz e Sehnem } \\
\text { (2016), Drebes e Spanevello (2017), Pires e Hoff (2018) e Santos (2018) }\end{array}$ \\
$\begin{array}{c}\text { As cooperativas oferecem } \\
\text { assistência técnica aos } \\
\text { cooperados }\end{array}$ & $\begin{array}{c}\text { Marschall (2009), Francio (2011), Raupp (2012), Pedon (2013), Binda (2014), Vendrame } \\
\text { (2014), Nascimento (2015), Simioni, Binotto e Battiston (2015), Melz e Sehnem (2016), } \\
\text { Bangel (2017), Breitenbach, Brandão e Zorzan (2017), Ferreira et al. (2018), e Guedes (2018) }\end{array}$ \\
$\begin{array}{c}\text { As cooperativas facilitam o } \\
\text { acesso à informação } \\
\text { relevante para suas } \\
\text { atividades }\end{array}$ & $\begin{array}{c}\text { Pereira (2008), Marschall (2009), Santos (2010), Francio (2011), Andersson, Mauch e Bezerra } \\
\text { (2012), Santos e Cândido (2013), Xavier (2013), Binda (2014), Valandro (2014), Vendrame } \\
\text { (2014), Nascimento (2015), Rodrigues (2015), Simioni, Binotto e Battiston (2015), Melz e } \\
\text { Sehnem (2016), Tenzin e Natsuda (2016), Bangel (2017), Drebes e Spanevello (2017), } \\
\text { Mallmann (2017) e Santos (2018) }\end{array}$ \\
\hline $\begin{array}{c}\text { As cooperativas favorecem a } \\
\text { adoça de práticas de gestão } \\
\text { por parte dos cooperados }\end{array}$ & $\begin{array}{c}\text { Simioni, Binotto e Battiston (2015), Melz e Sehnem (2016), Tenzin e Natsuda (2016) e } \\
\text { Drebes e Spanevello (2017) }\end{array}$ \\
\hline
\end{tabular}

Figura 4. Variáveis do constructo Conhecimento da dimensão social da sustentabilidade Fonte: Dados da pesquisa (2020)

$\mathrm{Na}$ abordagem sobre o constructo Conhecimento, na Figura 4, verifica-se que as cooperativas facilitam o acesso à informação para agricultura familiar, oferecendo cursos para capacitação e incentivando a busca pelo conhecimento, favorecendo a adoção de práticas de gestão, além de oferecerem assistência técnica (Melz \& Sehnem, 2016; Breitenbach, Brandão, \& Zorzan, 2017; Mallmann, 2017). Destarte, possibilita o desenvolvimento de uma nova hipótese.

Hipótese 3 (H3): a cooperativa influencia positivamente no conhecimento na dimensão social da sustentabilidade dos cooperados da agricultura familiar.

Definida a terceira hipótese do estudo, na Figura 5 apresentam-se as variáveis do constructo Comercialização da dimensão social da sustentabilidade proporcionada pelas cooperativas para a agricultura familiar.

\begin{tabular}{|c|c|}
\hline Variáveis & Referências \\
\hline $\begin{array}{c}\text { As cooperativas propiciam o } \\
\text { comércio justo }\end{array}$ & Santos (2010), Davila e Molina (2016) e Casagrande e Begnini (2018) \\
\hline $\begin{array}{l}\text { As cooperativas apresentam } \\
\text { maior segurança para a } \\
\text { agricultura familiar no } \\
\text { processo de negociação }\end{array}$ & $\begin{array}{c}\text { Pereira (2008), Marschall (2009), Garcia (2011), Raupp (2012), Santos e Cândido (2013), Silva, } \\
\text { Barbosa e Albuquerque (2013), Xavier (2013), Binda (2014), Vendrame (2014), Davila e } \\
\text { Molina (2016) e Tenzin e Natsuda (2016) }\end{array}$ \\
\hline $\begin{array}{l}\text { As cooperativas facilitam o } \\
\text { acesso aos programas } \\
\text { governam entais para } \\
\text { comercialização }\end{array}$ & $\begin{array}{c}\text { Miranda (2008), Gotuzzo (2009), Alves et al. (2011), Francio (2011), Andrade e Alves (2013), } \\
\text { Dias et al. (2013), Pedon (2013), Santos e Cândido (2013), Silva (2013), Silva, Barbosa e } \\
\text { Albuquerque (2013), Xavier (2013), Binda (2014), Arruda et al. (2015), Kunzler (2015), } \\
\text { Nascimento (2015), Paetzold (2015), Kunzler e Badalotti (2017), Santos, Rodrigues e } \\
\text { Medina (2017), Casagrande e Begnini (2018), Ferreira et al. (2018), Guedes (2018), Pires e } \\
\text { Hoff (2018) e Santos et al. (2018) }\end{array}$ \\
\hline $\begin{array}{l}\text { As cooperativas oferecem } \\
\text { atendimento de melhor } \\
\text { qualidade em relação ao } \\
\text { mercado }\end{array}$ & Marschall (2009) e Freitas, Amodeo e Silva (2012) \\
\hline
\end{tabular}

Figura 5. Variáveis do constructo Comercialização da dimensão social da sustentabilidade Fonte: Dados da pesquisa (2020) 
$\mathrm{Na}$ Figura 5, quanto ao constructo Comercialização, verifica-se que as cooperativas conseguem apresentar maior nível de segurança para as negociações da agricultura familiar, além de oferecer melhor atendimento, auxiliando no processo de negociação, e também ao acesso dos agricultores familiares aos programas governamentais, facilitando assim às vendas, e propiciam o comércio justo (Silva, Barbosa, \& Albuquerque, 2013; Molina, 2016; Santos et al., 2018). Finalizando os constructos pertencentes aos constructos da dimensão social formula-se a quarta hipótese da pesquisa.

Hipótese 4 (H4): a cooperativa influencia positivamente na comercialização na dimensão social da sustentabilidade dos cooperados da agricultura familiar.

Com as hipóteses dos constructos da dimensão social formados, tem-se a formulação da última hipótese da dimensão social, a décima do estudo, a qual envolve as quatro hipóteses anteriores.

Hipótese 5 (H5): a cooperativa influencia positivamente na dimensão social da sustentabilidade dos cooperados da agricultura familiar.

Com a fundamentação teórica apresentada tem-se uma base do tema em análise na presente pesquisa, possibilitando maior nível de entendimento para sequência do estudo e propiciando a formulação das hipóteses. Dando continuidade, no próximo capítulo é apresentada a metodologia da pesquisa.

\section{Procedimentos metodológicos}

No presente estudo, quanto aos objetivos, a pesquisa se classificou como exploratória, este tipo de pesquisa tem por objetivo proporcionar maiores informações sobre o assunto que será analisado, buscando torná-lo mais explícito (Gil, 2010).

Considerando a fase de coleta de informações junto à população pesquisada, este estudo se classificou como um levantamento, que é uma pesquisa que envolve a investigação direta, com intuito de obter informações a respeito da população e do assunto que se quer conhecer, para que com esses dados se realize uma análise quantitativa, possibilitando chegar às conclusões sobre o tema (Gil, 2010).

E por fim, como abordagem da pesquisa foi utilizado o método quantitativo para coleta e análise dos dados, que para Kauark, Manhães e Medeiros (2010) este tipo de pesquisa transforma tudo que pode ser quantificado em números, para posteriormente poder analisar e classificar esses dados. Quanto ao tratamento dos dados, o mesmo é feito por técnicas estatísticas.

A amostra do estudo foi composta pelos associados da Cooperativa de Leite da Agricultura Familiar com Interação Solidária (COOPLAF), localizada no Reassentamento São Francisco, pertencente a cidade de Cascavel - PR, na região oeste do Paraná, esta que foi a cooperativa foco desta pesquisa. A cooperativa possui 51 associados, desta forma, como foi realizada a comparação entre os cooperados e os que não são cooperados, então foi necessário aplicar questionários para 51 indivíduos que não são cooperados da COOPLAF e que tem suas propriedades no Reassentamento São Francisco, ao total foram 102 indivíduos que fizeram parte da amostra da pesquisa. Segundo a cooperativa, são aproximadamente 200 famílias que vivem no reassentamento.

A seleção dos respondentes cooperados foi por conveniência, já que foram selecionados todos os cooperados, pois o autor escolheu este grupo para participar da pesquisa, já para os não cooperados a coleta foi realizada na forma de amostragem probabilística, que conforme Richardson, Peres, Wanderley, Correia e Peres (2012) é definida dessa forma quando a probabilidade de qualquer indivíduo da população fazer parte da amostra não é igual a zero, ou seja, o elemento tem a possibilidade de fazer parte da amostra.

\section{Procedimentos de coleta de dados}

A forma de coleta de dados usada no estudo foi o questionário, que segundo Kauark, Manhães e Medeiros (2010) é um instrumento de coleta de dados para pesquisa por meio de questões predeterminadas e em 
sequência. Gil (2010) salienta que esta forma de coleta tem o intuito de obter informações sobre sentimentos, valores, conhecimentos e comportamentos.

Para o desenvolvimento do questionário foram tomadas como base as pesquisas similares, conforme apresentadas no Capítulo "Estudos similares", em que cada uma das contribuições apresentadas foi uma questão. Destas pesquisas, algumas apresentaram questionários, nos quais foram adaptadas as questões para o presente estudo, mas em sua maior parte as contribuições das cooperativas para a agricultura familiar foram identificadas nas conclusões dos trabalhos, os quais apresentaram essas contribuições, e estas foram selecionadas para compor o questionário desta pesquisa.

Para mensurar as opiniões dos respondentes, em cada uma das variáveis do questionário foram utilizadas escalas de Likert (1932), considerando as opções: discordo totalmente; discordo; não concordo nem discordo; concordo; e concordo totalmente.

No início do questionário há uma introdução explicando sobre o estudo e também campos para preenchimento do perfil socioeconômico dos respondentes, esta seção contém 6 perguntas. O questionário foi composto por 28 questões, sendo 22 questões referentes à dimensão social da sustentabilidade. Foram utilizadas todas as variáveis encontradas na literatura sobre a sustentabilidade social, estas que foram necessárias para verificar o que se dispôs a analisar neste estudo, que foi investigar se a cooperativa influencia na dimensão social da sustentabilidade da agricultura familiar.

A aplicação dos questionários foi realizada de forma direta, em que o pesquisador se dirigiu para a propriedade de cada um dos indivíduos para aplicar os questionários de forma individual, no qual o pesquisador ficou aguardando os respondentes finalizarem os questionários, auxiliando quando necessário em alguma dúvida que pudesse surgir por parte dos respondentes.

Os questionários foram entregues em documentos impressos, sendo 51 questionários para cooperados e 51 questionários para não cooperados. Ao total foram 102 indivíduos que fizeram parte da pesquisa. Nem todos os agricultores familiares não cooperados estavam dispostos a responder o questionário, em que foram visitados 69 não cooperados, destes, 51 responderam o questionário. Esta etapa de coleta de dados iniciou no dia 01 de novembro de 2019 e finalizou no dia 06 de março de 2020.

\section{Procedimentos de análise de dados}

Primeiramente, para análise dos dados, todas as informações dos questionários coletados foram tabuladas no software Excel e depois repassadas para o software SmartPLS ${ }^{\circledR}$ 3.0, para que nele pudesse ser realizada a análise dos dados pela Modelagem de Equações Estruturais (Structural Equation Models SEM), com estimação dos "Mínimos Quadrados Parciais" (Partial Least Square - Path modelling - PLSPM). Esta técnica permite explicar a relação entre múltiplas variáveis, examinando a estrutura de interrelações expressas em uma série de equações, possibilitando realizar análises mais amplas sobre os dados obtidos, observando as relações existentes entre as múltiplas variáveis, latentes ou observadas, de forma simultânea (Hair Jr., Hult, Ringle, \& Sarstedt, 2016).

Com a análise da Modelagem de Equações Estruturais é possível verificar se as variáveis que compõem o estudo representam os constructos conforme foram apresentados no Capítulo "Estudos similares" (Hair Jr. et al., 2016). A análise é composta por duas etapas, a primeira se constitui na validação do modelo formativo, e na segunda avalia-se o modelo estrutural. Todos os cálculos são realizados diretamente pelo software ao inserir os dados e solicitar as análises necessárias.

$\mathrm{Na}$ validação do modelo formativo realiza-se a verificação do modelo de mensuração, analisando os indicadores de validade convergente e discriminante, e medindo a relação existente entre os constructos latentes e as variáveis observadas (Ringle, Silva, \& Bido, 2014).

Conforme Hair Jr. et al. (2016), na análise da validade convergente se verifica como os indicadores se correlacionam positivamente com as demais variáveis do mesmo constructo. Para isso são analisadas as 
cargas fatoriais externas, considerando os valores da Variância Média Extraída (AVE), e para verificar a consistência interna são utilizados os resultados do Alfa ( $\alpha$ ) de Cronbach (AC) e da Confiabilidade Composta (CC).

Para o valor das AVEs utilizou-se o critério de Fornell e Larcker (1981), os quais consideram que os valores devem ser maiores que 0,50 (AVE $>0,50$ ). A AVE demonstra o quanto as variáveis se correlacionam positivamente com os seus respectivos constructos. Um valor de AVE que seja maior que 0,5 indica que o constructo explica ao menos a metade da variância de seus indicadores.

Em relação ao AC e a CC, estes demonstram se as respostas são confiáveis, livre de vieses. Para o AC, valores acima de 0,60 são considerados adequados, já para a CC, valores acima de 0,70 a 0,90 são considerados satisfatórios (Hair Jr. et al., 2016).

$\mathrm{Na}$ validade discriminante, verifica-se se os constructos são independentes uns dos outros, comparando as raízes quadradas dos valores das AVEs de cada constructo com as correlações entre as variáveis latentes (Hair Jr. et al., 2016).

Para a análise do modelo estrutural, utiliza-se os coeficientes de determinação $\left(\mathrm{R}^{2}\right)$, que demonstra o poder explanatório e a qualidade do modelo ajustado (Hair Jr. et al., 2016), e também é avaliada a relevância preditiva do modelo por meio do valor de $\mathrm{Q}^{2}$, verificando quanto o modelo se aproxima do que era esperado dele (Ringle, Silva, \& Bido, 2014). Outro coeficiente para esta análise é o f ${ }^{2}$, que busca avaliar quanto cada constructo contribui para o modelo (Hair Jr. et al., 2016).

$\mathrm{Na}$ última análise, a qual foi utilizada para realizar o teste de hipóteses, foram avaliados os coeficientes de caminho do modelo estrutural, que demonstram uma comparação entre coeficientes, indicando o poder relativo de explicação da variável dependente (Hair, Babin, Money, \& Samouel, 2005). E para esta análise devem ser observados os valores do teste t-student e do p-valor, para verificar se os dados são significativos, que para este estudo foi utilizado o nível de significância de $5 \%$, como comumente utilizado em estudos nas ciências sociais.

Para o teste de hipóteses utilizou-se dos constructos validados e realizou-se a comparação com a variável dos Cooperados, esta que é uma variável dummy, na qual as opções de resposta foram: Cooperado (valor 1) ou Não cooperado (valor 0), assim uma correlação positiva significa que a opinião dos cooperados é mais positiva do que a dos não cooperados e uma correlação negativa significa que a opinião dos não cooperados é mais positiva do que a dos cooperados.

A escolha do método se justifica, pois, pelo uso dele é possível identificar relações que dificilmente seriam identificadas por outro método, já que possibilita a relação entre múltiplas várias concomitantemente (Hair Jr. et al., 2016).

Com a análise foi possível comparar os grupos de cooperados e não cooperados, verificando se existe diferença entre a sustentabilidade deles de acordo com as contribuições que a cooperativa propicia, ou seja, foi verificado se na percepção dos agricultores familiares cooperados a cooperativa auxilia na melhoria da sua sustentabilidade social, e para os não cooperados se estas mesmas variáveis estão sendo atingidas sem ter relação com a cooperativa, assim, buscou-se chegar ao foco desta pesquisa, verificando se a cooperativa tem influência na dimensão social da sustentabilidade dos cooperados da agricultura familiar, que seja diferente da percepção dos não cooperados.

\section{Apresentação e análise dos resultados}

Neste capítulo são apresentados os resultados, em que na primeira seção foi realizada a validação dos constructos, com a Modelagem de Equações Estruturais (Structural Equation Models - SEM), onde se verificou se as variáveis observadas representam os constructos, já que estes por sua vez não são medidos diretamente, mas sim indiretamente por meio de cada variável observada (Hair Jr. et al., 2016). 
Em segundo momento, na seção de teste de hipóteses, são comparadas as percepções entre cooperados e não cooperados em relação aos benefícios proporcionados pela cooperativa para a agricultura familiar, buscando assim atingir o objetivo de pesquisa.

A divisão foi realizada buscando simplificar o entendimento, pois em primeiro momento serão analisados somente os constructos com as variáveis observadas, etapa na qual serão eliminadas questões, se necessárias, para que atendam aos requisitos mínimos de aceitabilidade, com base na literatura, para composição dos constructos finais, para que assim, em segundo momento sejam analisados estes constructos com a variável dos agricultores familiares serem cooperados ou não, já que nesta etapa não foram eliminadas variáveis, mas sim, verificou-se se elas são suportadas ou não para atendimento das hipóteses de pesquisa.

\section{Validação dos constructos}

A primeira etapa da análise consistiu-se na validação do modelo formativo, em que se realiza a verificação do modelo de mensuração, o qual inclui análise dos indicadores de validade convergente e discriminante, e mede a relação existente entre os constructos latentes e as variáveis observadas.

$\mathrm{Na}$ análise das cargas fatoriais é recomendado que os valores sejam superiores a 0,5, mas, preferencialmente, acima de 0,7. Para maior rigor na obtenção dos resultados, nesta pesquisa foram aceitos somente valores acima de 0,7, eliminando valores menores, pois, quantos maiores as cargas fatoriais, mais assertivo estar-se-á de que as variáveis convergem para um ponto comum dentro do constructo (Hair Jr. et al., 2016). No momento foram avaliadas as cargas fatoriais das variáveis observadas, já as cargas entre as variáveis latentes serão analisadas no fim do processo de análise.

Na sequência foi realizada a análise da dimensão social, em que na Figura 6 é apresentado o seu modelo de mensuração.

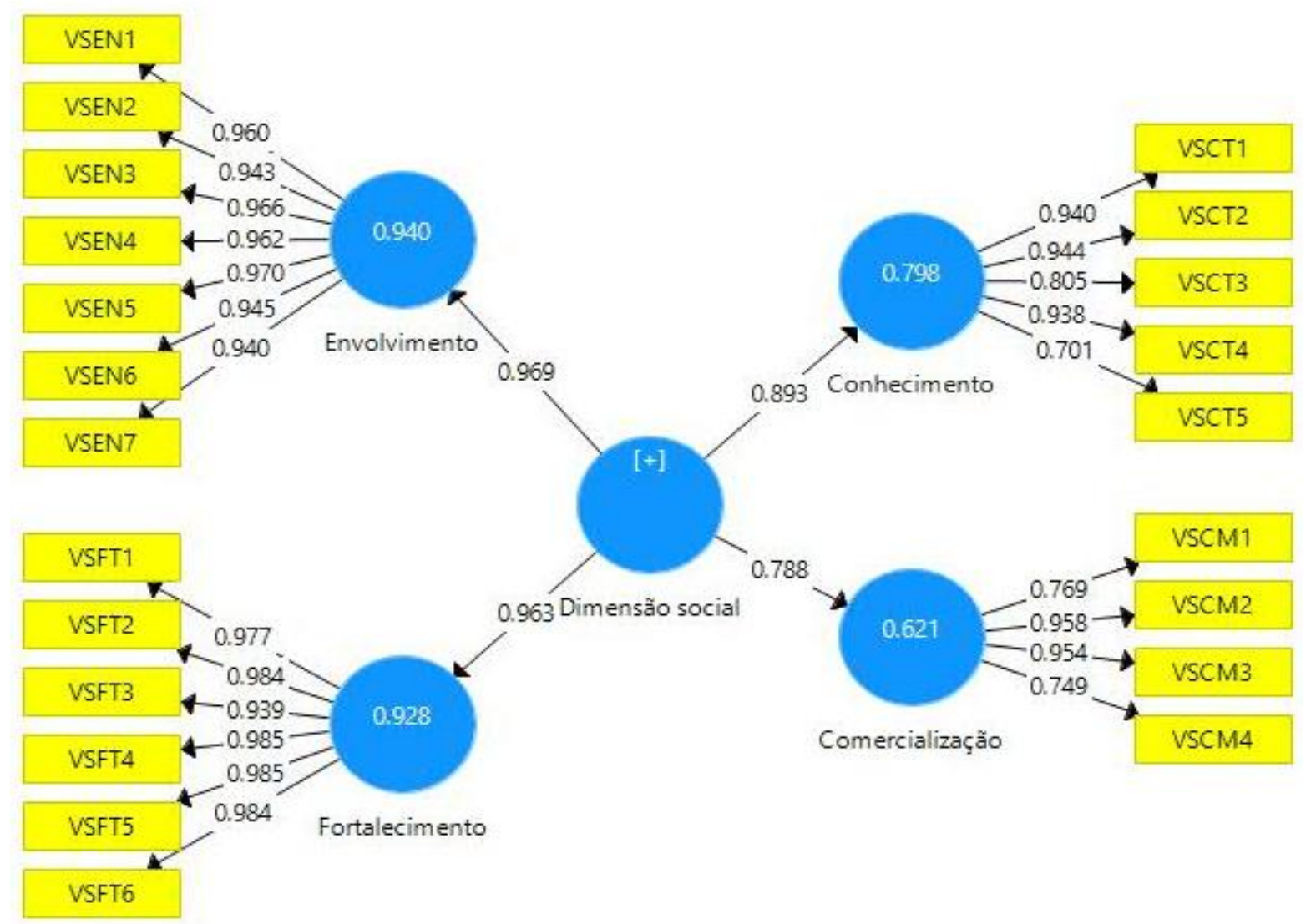

Figura 6. Modelo de mensuração da dimensão social

Fonte: Dados da pesquisa (2020) 
Conforme observado na Figura 6, não foi necessário eliminar variáveis, pois todos as cargas fatoriais ficaram acima de 0,7 , sendo todas excelentes, o que indica que todas as variáveis estão alinhadas, não tendo muitas variações de respostas entre os questionados dentro de cada constructo. Passa-se então para a segunda análise, na Tabela 1 são apresentados os coeficientes de confiabilidade.

Tabela 1. Análise de confiabilidade dos constructos da dimensão social

\begin{tabular}{cccc}
\hline Constructo & $\begin{array}{c}\text { Alfa de } \\
\text { Cronbach (AC) }\end{array}$ & $\begin{array}{c}\text { Confiabilidade } \\
\text { Composta (CC) }\end{array}$ & $\begin{array}{c}\text { Variância Média } \\
\text { Extraída (AVE) }\end{array}$ \\
\hline Comercialização & 0,882 & 0,920 & 0,745 \\
Conhecimento & 0,917 & 0,939 & 0,759 \\
Envolvimento & 0,984 & 0,986 & 0,912 \\
Fortalecimento & 0,990 & 0,992 & 0,952 \\
\hline
\end{tabular}

Fonte: Dados da pesquisa (2020)

Com a Tabela 1, verificou-se que todos os valores estão dentro da faixa aceitável, em que os valores do AC estão acima de 0,6, de CC acima de 0,7 , que demonstra confiança nos resultados, e os valores da AVE também estão acima de 0,5, indicando validade convergente, vale destacar que os valores do constructo Envolvimento e Fortalecimento ficaram bastante elevados, indicando que são importantes constructos do modelo. A próxima etapa trata da validade discriminante da dimensão social, conforme pode-se visualizar na Tabela 2 .

Tabela 2. Análise de validade discriminante dos constructos da dimensão social

\begin{tabular}{ccccc}
\hline Constructo & Comercialização & Conhecimento & Envolvimento & Fortalecimento \\
\hline Comercialização & $\mathbf{0 , 8 6 3}$ & & & \\
Conhecimento & 0,684 & $\mathbf{0 , 8 7 1}$ & & \\
Envolvimento & 0,667 & 0,829 & $\mathbf{0 , 9 5 5}$ & \\
Fortalecimento & 0,708 & 0,783 & 0,934 & $\mathbf{0 , 9 7 6}$ \\
\hline
\end{tabular}

Fonte: Dados da pesquisa (2020)

$\mathrm{Na}$ Tabela 2, a análise da validade discriminante demonstra que todos os valores apresentam correlações maiores consigo mesmo do que em relação aos outros constructos, indicando que os constructos possuem validade discriminante entre si. Para exemplificar, se um constructo obtivesse um valor maior de correlação em comparação a algum outro constructo do que com ele mesmo, não haveria então validade discriminante, e seria necessário retirar variáveis que apresentassem maior correlação entre estes constructos para que a validade discriminante fosse possível. Com isso finaliza-se a análise do modelo formativo da dimensão social, passando para análise do modelo estrutural. Para início da análise estrutural, na Tabela 3 são apresentados os valores $\mathrm{R}^{2}, \mathrm{Q}^{2}$ e $\mathrm{f}^{2}$.

Tabela 3. Análise do modelo estrutural dos constructos da dimensão social

\begin{tabular}{cccc}
\hline Constructo & $\mathbf{R}^{\mathbf{2}}$ ajustado & $\mathbf{C V} \mathbf{R E D}\left(\mathbf{Q}^{2}\right)$ & $\mathbf{C V} \mathbf{C O M}\left(\mathbf{f}^{2}\right)$ \\
\hline Comercialização & 0,617 & 0,439 & 0,577 \\
Conhecimento & 0,796 & 0,574 & 0,636 \\
Envolvimento & 0,939 & 0,852 & 0,878 \\
Fortalecimento & 0,927 & 0,878 & 0,923 \\
\hline
\end{tabular}

Fonte: Dados da pesquisa (2020)

Conforme os resultados da Tabela 3, tem-se que os valores de $\mathrm{R}^{2}$ podem ser considerados altos, demonstrando que os constructos têm forte poder explicativo. Os valores de $\mathrm{Q}^{2}$ são todos maiores que 0 , indicando que o modelo ajustado possui precisão. E os coeficientes de $\mathrm{f}^{2}$ também são altos, concluindo que o modelo tem grande efeito. Na última etapa avaliou-se os coeficientes de caminho do modelo estrutural, considerando a significância ao nível de 5\% ao observar os valores do p-valor e t-student, conforme é apresentado na Tabela 4. 
Percepções de cooperados e não cooperados em relação à dimensão social da sustentabilidade de uma cooperativa leiteira da agricultura familiar

Tabela 4. Coeficientes de correlação entre os constructos da dimensão social

\begin{tabular}{cccc}
\hline Relações & $\begin{array}{c}\text { Coeficiente de } \\
\text { caminho }\end{array}$ & $\boldsymbol{t}$-student & Valores de P \\
\hline Dimensão social $\rightarrow$ Comercialização & 0,788 & 14,084 & 0,000 \\
Dimensão social $\rightarrow$ Conhecimento & 0,893 & 42,842 & 0,000 \\
Dimensão social $\rightarrow$ Envolvimento & 0,969 & 135,933 & 0,000 \\
Dimensão social $\rightarrow$ Fortalecimento & 0,963 & 108,736 & 0,000 \\
\hline
\end{tabular}

Fonte: Dados da pesquisa (2020)

Com a Tabela 4 verificou-se que todos os valores são significativos e tem correlação positiva forte, o que indica que os constructos Comercialização, Conhecimento, Envolvimento e Fortalecimento são importantes para composição da dimensão social. Finaliza-se então a análise da validação dos constructos e inicia-se o teste de hipóteses.

\section{Teste de hipóteses}

Seguindo as análises, nesta seção são realizados os testes de hipóteses, em que inicialmente, para melhor visualização, foi apresentado o modelo de mensuração, considerando os constructos já validados e comparando-os com a variável dos Cooperados. Na Figura 7 é apresentado o modelo de mensuração demonstrando a relação dos Cooperados com a dimensão social da sustentabilidade.

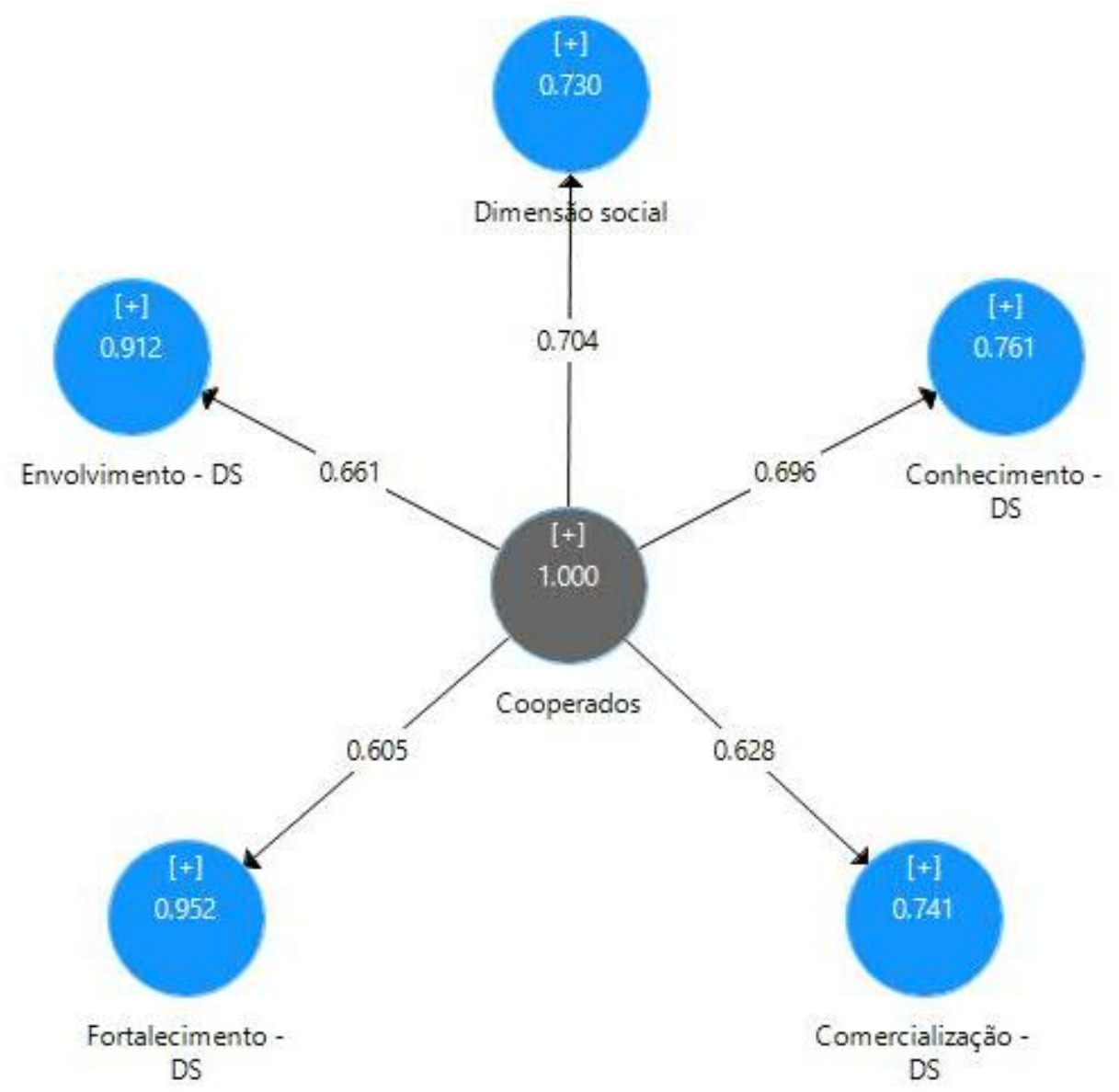

Figura 7. Modelo de mensuração da relação dos cooperados com a dimensão social da sustentabilidade Fonte: Dados da pesquisa (2020)

Com o apresentado na Figura 7, verificou-se que todos os coeficientes de caminho foram positivos, indicando existir diferença entre as opiniões dos cooperados com a dos não cooperados sobre a influência da cooperativa na dimensão social da sustentabilidade, considerando os constructos Envolvimento, Fortalecimento, Conhecimento e Comercialização. E para confirmar essa diferença de percepção, na 
Tabela 5 foi realizado o teste de hipóteses, considerando os valores do p-valor e t-student ao nível de significância de $5 \%$.

Tabela 5. Teste de hipóteses da dimensão social da sustentabilidade

\begin{tabular}{ccccc}
\hline Hipótese & Relações & Coeficiente de caminho & t-student & Valores de P \\
\hline H1 - Aceita & Cooperados $\rightarrow$ Envolvimento - DS & 0.661 & 15.719 & 0.000 \\
H2 - Aceita & Cooperados $\rightarrow$ Fortalecimento - DS & 0.605 & 10.745 & 0.000 \\
H3 - Aceita & Cooperados $\rightarrow$ Conhecimento - DS & 0.696 & 21.501 & 0.000 \\
H4 - Aceita & Cooperados $\rightarrow$ Comercialização - DS & 0.628 & 13.718 & 0.000 \\
H5 - Aceita & Cooperados $\rightarrow$ Dimensão social & 0.704 & 19.275 & 0.000 \\
\hline
\end{tabular}

Fonte: Dados da pesquisa (2020)

Por meio dos resultados da Tabela 5, tornou-se possível inferir que a cooperativa influencia positivamente no Envolvimento, Fortalecimento, Conhecimento e Comercialização na dimensão social da sustentabilidade dos cooperados da agricultura familiar, pois conforme os coeficientes obtidos, os valores de caminho são estatisticamente positivos na comparação das percepções dos cooperados com os não cooperados em relação à influência da cooperativa na agricultura familiar, o que indica que os cooperados tem maior reconhecimento quanto aos impactos da cooperativa do âmbito social da sustentabilidade, e com isso tem-se suporte para aceitar as hipóteses H1, H2, H3, H4 e H5.

Conforme foi apresentado no decorrer desta seção, todos os constructos obtiveram coeficiente de caminho positivo quando comparados com a variável dos cooperados, demonstrando que, de acordo com o grupo de respondentes desta pesquisa, existe distinção estatística entre cooperados e não cooperados, o que possibilitou inferir, alinhado com o objetivo de pesquisa, que, ser cooperado de uma cooperativa leiteira influencia na dimensão social da sustentabilidade da agricultura familiar.

A afirmação de que a cooperativa influencia na sustentabilidade dos cooperados é possível, pois como há uma diferença estatisticamente significativa e positiva quanto a opinião dos cooperados em relação aos não cooperados, tem-se que ser cooperado faz com que o agricultor familiar seja impactado positivamente com os benefícios da cooperativa, demonstrando a importância da cooperativa e de ser cooperado para a agricultura familiar. Com isso, findou-se a apresentação dos resultados, na próxima seção discutiu-se o que no presente tópico foi descrito.

\section{Discussões dos resultados}

Nesta seção foram discutidos os resultados encontrados, confrontando com o suporte teórico utilizado para elaboração das hipóteses, buscando concluir o objetivo estabelecido nesta pesquisa. Com a apresentação dos resultados é importante frisar que o presente estudo, diferente dos trabalhos citados no Capítulo "Estudos similares", realizou uma comparação entre cooperados e não cooperados de forma quantitativa, fortalecendo as teorias encontradas por estes estudos e demonstrando que, as cooperativas não atingem de forma igualitária toda a agricultura familiar, mas sim, tem maior impacto positivo quanto à sustentabilidade dos agricultores cooperados, fortalecendo a importância de fazer parte de uma cooperativa. Além do que, como em outros estudos não houve uma comparação entre cooperados e não cooperados, não era possível inferir de forma quantitativa que as cooperativas tinham impacto positivo na agricultura familiar para os cooperados.

Em relação à dimensão social, a qual foi dividida em quatro constructos, sobre o primeiro deles, o Envolvimento, identificou-se que a cooperativa contribui para o envolvimento social entre os cooperados, confirmando os estudos de Ternoski (2013), Boessio e Doula (2016) e Mallmann (2017), outra contribuição da cooperativa está relacionada com a colaboração dos cooperados entre eles, demonstrando que a cooperativa propicia a solidariedade entre os cooperados, conforme os estudos de Tokarski (2013), Arruda et al. (2015) e Kunzler e Badalotti (2017), a cooperativa também envolve os cooperados nas tomadas de decisão, estando alinhado com os trabalhos de Rodrigues (2015), Davila e Molina (2016) e Casagrande e Begnini (2018). 
A cooperativa tem um importante papel na sucessão familiar, incentivando que o jovem continue no campo, assim como identificado por Freitas e Freitas (2013), Bangel (2017) e Drebes e Spanevello (2017), e buscam pela equidade de gênero, incentivando a participação de mulheres, como em Xavier (2013) e Binda (2014). Outro aspecto importante, que envolve também a psicologia, está alinhado com a contribuição da cooperativa para com um maior nível de sentimento de pertença ao grupo, como verificado também por Marschall (2009), Silva, Barbosa e Albuquerque (2013) e Simioni, Binotto e Battiston (2015), e sentimento de pertença ao local em que vivem, seguindo o raciocínio de Marschall (2009), Pires e Hoff (2018) e Santos (2018).

Sobre o Fortalecimento, igualmente confirmou-se que a cooperativa contribui para com os cooperados para o desenvolvimento local e regional, corroborando com os estudos de Ignácio e Souza (2008), Winck et al. (2014) e Ferreira et al. (2018), contribuindo para o surgimento e expansão de novos empreendimentos, conforme salientado também por Santos (2010), Alves et al. (2011) e Vendrame (2014). A cooperativa ainda contribui com o combate da pobreza da agricultura familiar, estando alinhado às pesquisas de Gotuzzo (2009), Hahn (2014) e Santos, Rodrigues e Medina (2017), e a cooperativa também melhora a qualidade de vida da agricultura familiar, como visualizado por Miranda (2008), Francio (2011) e Silva (2013), além de fortalecer os cooperados da agricultura familiar, assim como identificado por Gonçalves da Silva (2013), Pedon (2013) e Kunzler (2015), e auxiliam na sobrevivência das culturas de pequena propriedade, estando de acordo com as pesquisas de Andersson, Mauch e Bezerra (2012), Vendrame (2014) e Santos (2018).

$\mathrm{Na}$ abordagem sobre o constructo do Conhecimento da dimensão social, a cooperativa facilita o acesso à informação relevante para as atividades da agricultura familiar, como visto por Santos e Cândido (2013), Valandro (2014) e Nascimento (2015), e oferecem-lhes cursos para a capacitação dos cooperados, tal como foi identificado por Valandro (2014), Simioni, Binotto e Battiston (2015) e Pires e Hoff (2018). A cooperativa também incentiva a busca pelo conhecimento dos cooperados, indo ao encontro das observações Andrade e Alves (2013), Melz e Sehnem (2016) e Santos (2018), além do que, favorecem a adoção de práticas de gestão por parte dos cooperados, estando de acordo com os resultados de Melz e Sehnem (2016), Tenzin e Natsuda (2016) e Drebes e Spanevello (2017), e ainda oferecem assistência técnica aos cooperados, como salientando por Raupp (2012), Binda (2014) e Guedes (2018).

Por fim, mas não menos importante, a cooperativa contribui com os cooperados quanto ao constructo da Comercialização da dimensão social, onde identificou-se que a cooperativa passa maior nível de sentimento de segurança nas negociações com a agricultura familiar, alinhado com os resultados de Pereira (2008), Garcia (2011) e Tenzin e Natsuda (2016), além de oferecer atendimento de melhor qualidade em relação ao mercado, como já havia sido mencionado por Marschall (2009) e Freitas, Amodeo e Silva (2012).

A cooperativa facilita o acesso dos agricultores familiares aos programas governamentais, facilitando nas vendas, semelhante aos resultados de Dias et al. (2013), Paetzold (2015) e Santos et al. (2018), e por meio dessa forma de trabalho da cooperativa, ela consegue propiciar o comércio justo, sem que nenhuma das partes ganhe de forma desproporcional sobre a outra, assim como verificado por Santos (2010), Davila e Molina (2016) e Casagrande e Begnini (2018).

Apresentados os quatro constructos da dimensão social, e sem a necessidade de exclusão de nenhuma questão de nenhum dos constructos, verificou-se que a cooperativa exerce influência positiva na dimensão social da sustentabilidade dos cooperados da agricultura familiar, sendo formada por 22 itens que envolveram questões relacionadas ao âmbito social. Com isso, fica nítido o quão importante a cooperativa é para com os cooperados da agricultura familiar, facilitando de modo geral quanto aos aspectos sociais, auxiliando à permanência do pequeno produtor no campo, como uma ajuda mútua, onde todos ganham (Silva \& Torres, 2020). 


\section{Considerações finais}

O presente estudo teve como objetivo investigar se o fato de ser cooperado ou não em uma cooperativa leiteira influencia na dimensão social da sustentabilidade da agricultura familiar. Considerando o objetivo e a pergunta de pesquisa, verificou-se junto aos agricultores familiares, sendo cooperados e não cooperados, as suas percepções quanto às contribuições da cooperativa para com os pequenos produtores. Destarte, obteve-se que a cooperativa exerce influência sobre os cooperados da agricultura familiar na dimensão social da sustentabilidade, já que por meio dos coeficientes estatísticos verificou-se que os cooperados consideram mais positivos os impactos da cooperativa sobre a agricultura familiar, quando comparados com os não cooperados, ou seja, é importante ser cooperado.

Quanto a contribuição teórica desta pesquisa, tem-se que, diferente dos trabalhos utilizados como suporte teórico deste estudo, foi abordada a dimensão social da sustentabilidade proporcionada pela cooperativa nas percepções dos cooperados e dos não cooperados da agricultura familiar, trazendo como diferencial teórico esta comparação, pois entende-se que somente desta forma é possível concluir quantitativamente que a cooperativa tem impacto sobre a agricultura familiar, que conforme identificado, o impacto é mais positivo para com os cooperados, que embora essa relação cooperativa e cooperado possa nem sempre ser a melhor economicamente, quanto ao aspecto social isso se difere, trazendo muitos benefícios nessa relação conforme salientado por Azevedo (2013), facilitando para a agricultura familiar se tornar sustentável no aspecto social (Silva \& Torres, 2020).

De acordo com Strahl (2019) a relação com as cooperativas se dá principalmente por aspectos econômicos, no entanto, deve se dar atenção para os aspectos sociais, pois são eles os que mais são impactados positivamente pelas cooperativas para com os cooperados, fortalecendo assim os resultados deste estudo, demonstrando que de fato para os cooperados as contribuições são evidenciadas de forma mais positiva, indicando que ser cooperado traz benefícios sociais para a sustentabilidade, deixando claro que são distintos os benefícios proporcionados pela cooperativa entre ser cooperado ou não, o que até então não era possível inferir, já que estes trabalhos apresentavam as contribuições das cooperativas como se estas colaborassem para a agricultura familiar como um todo, não evidenciando e fortalecendo a importância de ser cooperado.

Com a contribuição teórica apresentada, também se percebe que isto contribui para a prática, já que, como identificado, a cooperativa influencia a dimensão social da sustentabilidade. Desta forma, isto demonstra que a cooperativa tem importância para a permanência da agricultura familiar atuar de forma sustentável, pois ela valoriza o trabalho dos pequenos agricultores desfavorecidos pela competitividade, como argumentado por Brito, Gomes e Júnior (2021), e isto pode instigar para que os órgãos governamentais percebam a importância destas entidades, às beneficiando e fomentando para que se ampliem, e também quanto aos agricultores familiares que não são cooperados, este estudo serve de estímulo para que entendam que as cooperativas oferecem contribuições que podem colaborar com sua permanência na agricultura familiar de forma sustentável, quanto à sua dimensão social da sustentabilidade (Santos \& Cândido, 2013).

Como sugestão para trabalhos futuros, buscando reduzir as limitações deste estudo, sugere-se que este trabalho seja replicado em outras cooperativas, à fim de confrontar os resultados, já que os resultados da presente pesquisa não podem ser generalizados, pois o estudo foi realizado em um local específico, servindo como base para análise real da percepção destes agricultores familiares locais. Outra sugestão, em uma pesquisa de forma qualitativa, seria investigar quais são os principais motivos para que alguns agricultores familiares não sejam cooperados, ou se já foram e porque não são mais, assim como identificar o porquê destes que são cooperados, o serem.

Como pesquisa futura também é interessante comparar cooperativas de ramos diferentes e quais as principais contribuições de cada uma para com os seus cooperados, demonstrando que cada tipo de cooperativa tem uma função específica na sociedade, fortalecendo de forma diferente a dimensão social 
da sustentabilidade. Como principais conclusões da pesquisa, tem-se que é importante ser cooperado e que a cooperativa contribui com a dimensão social da sustentabilidade dos agricultores familiares.

Para atingir a sustentabilidade, é necessário que as práticas sustentáveis sejam adotadas por todos os envolvidos, ou seja, as ações devem ser feitas tanto pelas cooperativas como pelos agricultores familiares, cobrando e exigindo um do outro, com o objetivo de atingir o bem comum, a sustentabilidade, a qual possibilitará alongar a permanência em suas atividades, minimizando os impactos nas gerações futuras (Leripio, Alberton, Leripio, \& Riella, 2019).

\section{Referências}

Andersson, F. S., Mauch, C. R., \& Bezerra, A. A. (2012). O trabalho cooperativo e a agricultura familiar de base ecológica: atuações para um desenvolvimento sustentável a partir da realidade local. REDES: Revista do Desenvolvimento Regional, 17(3), 74-98.

Andrade, M. C., \& Alves, D. C. (2013). Cooperativismo e agricultura familiar: um estudo de caso. Revista de Administração IMED, 3(3), 194-208.

Alves, V. O., Vieira, N. S., Silva, T. C., \& Ferreira, P. R. (2011). O Associativismo na Agricultura Familiar dos Estados da Bahia e Minas Gerais: potencialidades e desafios frente ao Programa de Aquisição de Alimentos (PAA). Administração Pública e Gestão Social, 3(1), 66-88.

Arruda, A. S. O., Matos, F. R. N., Machado, D. D. Q., \& Arruda, C. D. B. (2015). Economia solidária e desenvolvimento local sustentável: um estudo de caso em um sistema de agricultura familiar. Organizações Rurais e Agroindustriais, 17(2), 163-178.

Assad, M. L. L., \& Almeida, J. (2004). Agricultura e sustentabilidade. Contexto, Desafios e cenários. Ciência e Ambiente. 29, 15-30.

Azevedo, V. G. (2013). Sustentabilidade da pesca direcionada ao Camarão-sete-barbas, Xiphopenaeus kroyeri (Heller, 1862), no litoral norte do Estado de São Paulo. Tese de doutorado, Universidade de São Paulo, São Paulo, SP, Brasil.

Bangel, S. M. C. (2017). Sucessão da Produção Agrícola Familiar: Ações Estratégicas Utilizadas pela Cooperativa de Laticínios Piá de Nova Petrópolis/RS. Dissertação de mestrado, Faculdades Integradas de Taquara, Taquara, RS, Brasil.

Barbieri, J. C., Vasconcelos, I. F. G. D., Andreassi, T., \& Vasconcelos, F. C. D. (2010). Inovação e sustentabilidade: novos modelos e proposições. Revista de Administração de Empresas - RAE, 50(2), 146154.

Binda, N. (2014). Cooperativismo agrícola: esfera pública, participação e sustentabilidade. Tese de doutorado, Universidade Federal do Rio Grande do Sul, Porto Alegre, PR, Brasil.

Boessio, A. T., \& Doula, S. M. (2016). Jovens rurais e influências institucionais para a permanência no campo: um estudo de caso em uma cooperativa agropecuária do Triângulo Mineiro. Interaçoes (Campo Grande), 17(3), 370-383.

Breitenbach, R., Brandão, J. B., \& Zorzan, M. (2017). Vantagens e oportunismo no relacionamento entre associados e cooperativa de laticínios. Interacões (Campo Grande), 18(2), 45-58.

Brito, J. D., Gomes, C. A. S., \& Júnior, P. D. S. P. (2021). Cooperativismo e comércio justo: a visão dos cooperados sobre mecanismos de Compliance. Brazilian Journal of Development, 7(3), 29159-29177.

Brundtland, G. H., Khalid, M., Agnelli, S., \& Al-Athel, S. (1987). Our common future. New York.

Casagrande, A., \& Begnini, S. (2018). Empreendimentos de Economia Solidária: Território Oeste Catarinense. Interações (Campo Grande), 19(1), 181-192.

Davari, M. R., Ram, M., Tewari, J., \& Kaushish, S. (2010). Impact of agricultural practice on ecosystem services. International journal of Agronomy and Plant Production, 1(1), 11-23.

Dávila, A., \& Molina, C. (2017). From silent to salient stakeholders: A study of a coffee cooperative and the dynamic of social relationships. Business \& Society, 56(8), 1195-1224. 
Dias, T. F., Nunes, E. M., Torres, F. L., \& Torres, A. C. M. (2013). Programa de Aquisição de Alimentos da Agricultura Familiar (PAA) como estratégia de inserção socioeconômica: o caso do Território da Cidadania Sertão do Apodi (RN). Revista Brasileira de Gestão e Desenvolvimento Regional, 9(3).

Drebes, L. M., \& Spanevello, R. M. (2017). Cooperativas agropecuárias e o desafio da sucessão na agricultura familiar. HOLOS, 2, 360-374.

Elkington, J. (1998). Partnerships from cannibals with forks: The triple bottom line of 21st-century business. Environmental Quality Management, 8(1), 37-51.

Esteves Neto, J. I. (2014). Desenvolvimento de indicadores da componente fauna-terrestre em contexto agricola: reunião de uma metodologia de avaliação da sustentabilidade. Dissertação de mestrado, Universidade do Porto, Porto, Portugal.

Ferreira, G. M. V., Von Ende, M., Rossés, G. F., \& Neumann, P. S. (2018). O cooperativismo como estratégia de inserção dos assentados da reforma agrária nos mercados dinâmicos: o caso da COPERTERRA. Revista de Administração da UFSM, 11(5), 1164-1181.

Fornell, C., \& Larcker, D. F. (1981). Evaluating structural equation models with unobservable variables and measurement error. Journal of Marketing Research, 18(1), 39-50.

Francio, N. (2011). Solidariedade, trabalho e renda: um estudo no Assentamento Wesley Manoel dos Santos. Dissertação de mestrado, Universidade do Vale do Rio dos Sinos, São Leopoldo, RS, Brasil.

Freitas, A. F., Amodeo, N. B. P., \& Silva, F. D. (2012). Crédito Solidário e Desenvolvimento Local: o caso da Cooperativa de Crédito da Agricultura Familiar e Economia Solidária de Araponga-MG. Desenvolvimento em Questão, 10(19).

Freitas, A. F., \& Freitas, A. F. (2015). Interações entre organizações coletivas na promoção do desenvolvimento local. Interações (Campo Grande), 14(2).

Freitag, C., Klesener, H. M., \& Plein, C. (2019). Contribuições do cooperativismo solidário para agricultura familiar e o desenvolvimento rural sustentável. Orbis Latina, 9(1), 95-109.

Galdeano-Gómez, E., Aznar-Sánchez, J. A., Pérez-Mesa, J. C., \& Piedra-Muñoz, L. (2017). Exploring synergies among agricultural sustainability dimensions: An empirical study on farming system in Almería (Southeast Spain). Ecological Economics, 140, 99-109.

Garcia, S. S. (2011). Cooperativismo de crédito: atuação da CRESOL como fator de desenvolvimento socioeconômico e combate à pobreza na região Sul / RS. Dissertação de mestrado, Universidade Católica de Pelotas, Pelotas, RS, Brasil.

Giagnocavo, C., Galdeano-Gómez, E., \& Pérez-Mesa, J. (2018). Cooperative longevity and sustainable development in a family farming system. Sustainability, 10(7), 2198.

Gil, A. C. (2010). Como elaborar projetos de pesquisa. 5 Ed. São Paulo: Atlas.

Gonçalves da Silva, G. (2013). Cooperação entre atores da agricultura familiar: o caso da cooperativa COOPGRANDE no município de Campo Grande - MS. Dissertação de mestrado, Universidade Federal do Mato Grosso do Sul, Campo Grande, MS, Brasil.

Gotuzzo, G. L. (2009). O papel das Organizações de Economia Solidária na promoção da sustentabilidade dos Agricultores Familiares Agroecológicos da região de Pelotas. Dissertação de mestrado, Universidade Católica de Pelotas, Pelotas, RS, Brasil.

Guedes, M. J. L. (2018). Influência do Programa de Aquisição de Alimentos (PAA) na sustentabilidade da agricultura familiar em Pernambuco. Dissertação de mestrado, Universidade Federal Rural de Pernambuco, Recife, PE, Brasil.

Hahn, K. G. (2014). Cooperativismo de crédito solidário: um estudo de caso CRESOL Ampére - PR. Dissertação de mestrado, Universidade Estadual do Oeste do Paraná, Marechal Cândido Rondon, PR, Brasil.

Hair, J. F., Babin, B., Money, A. H., \& Samouel, P. (2005). Fundamentos de métodos de pesquisa em administração. Porto Alegre: Bookman. 
Hair Jr, J. F., Hult, G. T. M., Ringle, C., \& Sarstedt, M. (2016). A primer on partial least squares structural equation modeling (PLS-SEM). Sage publications.

Ignácio, O. M. C., \& Souza, E. M. S. (2008). Gestão estratégica aplicada ao cooperativismo solidário: uma alternativa de fortalecimento para os agricultores familiares. Revista Brasileira de Gestão e Desenvolvimento Regional, 4(4).

Kauark, F. D. S., Manhães, F. C., \& Medeiros, C. H. (2010). Metodologia da pesquisa: um guia prático. Itabuna: Via Litterarum,

Kunzler, L. L. (2015). Cooperação como estratégia de viabilização da agricultura familiar: um estudo sobre a atuação da Cooperativa Central Sabor Colonial. Dissertação de mestrado, Universidade Comunitária da Região de Chapecó, Chapecó, SC, Brasil.

Kunzler, L. L., \& Badalotti, R. M. (2017). Cooperação alternativa como estratégia de viabilização da agricultura familiar: o caso da Cooperativa Central Sabor Colonial. Desenvolvimento em Questão, 15(39), 320352.

Leripio, D. P. D. L. C., Alberton, A., Leripio, A. D. A., \& Riella, J. (2019). Sustentabilidade territorial e corporativa por meio de sistemas de avaliação de desempenho por indicadores. Revista Alcance, 26(3), 300319.

Likert, R. (1932). A technique for the measurement of attitudes. Archives in Psychology, 140, 1-55.

Mallmann, L. M. (2017). Agricultores familiares e cooperativas: relações sociais de produção na cadeia produtiva do leite na região do Vale do Taquari/RS - Brasil. Tese de doutorado, Universidade de Santa Cruz do Sul, Santa Cruz do Sul, RS, Brasil.

Marschall, C. R. (2009). Motivações para o cooperativismo na pequena propriedade. Organiz̧ações \& Sociedade, 16(49).

Melz, M., \& Sehnem, S. (2016). Ferramentas de gestão que auxiliam na tomada de decisão e elevam a produtividade. O caso das granjas de suínos integradas a uma cooperativa. Agroalimentaria, 22(43), 165181.

Miranda, I. C. A. (2008). Avaliação da sustentabilidade dos programas de financiamento rural para o desenvolvimento rural do Estado do Ceará: estudo de caso. Dissertação de mestrado, Universidade Federal do Ceará, Fortaleza, CE, Brasil.

Munck, L., Bansi, A. C., Dias, B. G., \& Cella-de-Oliveira, F. A. (2013). Em busca da sustentabilidade organizacional: a proposição de um framework. Revista Alcance, 20(4), 460-477.

Nascimento, D. T. (2015). Programa de aquisição de alimentos (PAA): proposta de modelo de avaliação de satisfação (MAS) dos agricultores familiares sobre os aspectos operacionais e socioeconômicos. Dissertação de mestrado, Universidade Estadual do Oeste do Paraná, Cascavel, PR, Brasil.

Paetzold, L. J. (2015). Representatividade da Cooperativa de Crédito e o Programa Mais Alimentos: Resultados e Expectativas na Agricultura Familiar. Dissertação de mestrado, Universidade do Oeste de Santa Catarina, Chapecó, SC, Brasil.

Pedon, J. S. (2013). Cooperativas Sustentáveis no Estado de Rondônia: Em busca de Estratégias para o fortalecimento da Agricultura Familiar. Dissertação de mestrado, Fundação Universidade Federal de Rondônia, Porto Velho, RO, Brasil.

Pereira, A. B. (2008). Cooperativismo de crédito rural e sua influência no desenvolvimento local: estudo de caso da SICOOB Sertão, Pintadas-BA. Dissertação de mestrado, Universidade Salvador, Salvador, BA, Brasil.

Pires, M. A. P., \& Hoff, S. (2018). A Cooperativa dos Agricultores do Assentamento Itamarati II: Mediação entre o Estado e os Produtores. Desenvolvimento em Questão, 16(45), 336-353.

Portal Brasil. (2015). Agricultura familiar produz 70\% dos alimentos consumidos por brasileiro. Disponível em: $<$ http://www.brasil.gov.br/economia-e-emprego/2015/07/agricultura-familiar-produz-70-dosalimentos-consumidos-por-brasileiro> Acesso em: 13 de fevereiro de 2019. 
Raupp, I. D. (2012). Redes de cooperação: um estudo sobre a criação e captura de valor por produtores de hortaliças no Oeste do Paraná. Dissertação de mestrado, Universidade Estadual do Oeste do Paraná, Toledo, PR, Brasil. Richardson, R. J., Peres, J. D. S., Wanderley, J., Correia, L., \& Peres, M. (2012). Pesquisa social: métodos e técnicas. 14. reimpr. São Paulo: Atlas.

Riedner, L. N., Bertolini, G. R. F., Ribeiro, I., \& Brandalise, L. T. (2018). Avaliação da dimensão ambiental da sustentabilidade da agricultura familiar no oeste do estado do Paraná. Revista Metropolitana de Sustentabilidade, 8(1), 52-71.

Ringle, C. M., Silva, D., \& Bido, D. D. S. (2014). Modelagem de equações estruturais com utilização do SmartPLS. Revista Brasileira de Marketing, 13(2), 56-73.

Rodrigues, L. M. S. (2015). Agentes comunitários e cooperativismo solidário: o caso da Cresol de Francisco Beltrão. Dissertação de mestrado, Universidade Tecnológica Federal do Paraná, Pato Branco, PR, Brasil.

Sachs, I. (2008). Caminhos para o desenvolvimento sustentável. 3 Ed. Rio de Janeiro: Garamond.

Santos, A. C. V. (2018). A contribuição do cooperativismo de crédito solidário no fortalecimento da identidade territorial: o caso do sistema ASCOOB e sua atuação no território do Sisal, Bahia. Caderno de Geografia, 28(52), 106-124.

Santos, F. S. (2010). Momentos de Empowerment: Estratégias de pequenos produtores cooperados vinculados à agricultura familiar no Rio Grande do Sul. Dissertação de mestrado, Universidade Federal do Rio Grande do Sul, Porto Alegre, RS, Brasil.

Santos, J. G., \& Cândido, G. A. (2013). Sustentabilidade e agricultura familiar: um estudo de caso em uma associação de agricultores rurais. Revista de Gestão Social e Ambiental, 7(1), 70-86.

Santos, L. F., Campos, A. P. T., Ferreira, M. A. M., \& Freitas, A. F. (2018). Implicações das redes sociais para o acesso às políticas públicas: análise em cooperativas da agricultura familiar. Revista Brasileira de Gestão e Desenvolvimento Regional, 14(1), 329-353.

Santos, M. P., Rodrigues, J., \& Medina, G. (2017). Cooperativismo em Goiás: como equalizar competitividade e solidariedade? Interações (Campo Grande), 18(4), 31-42.

Simioni, F. J., Binotto, E., \& Battiston, J. (2015). Informação e gestão na agricultura familiar da região Oeste de Santa Catarina. Revista Brasileira de Gestão e Desenvolvimento Regional, 11(3).

Silva, D. B. (2012). Sustentabilidade no Agronegócio: dimensões econômica, social e ambiental. Comunicaşão \& Mercado, 1(3), 23.

Silva, V. (2013). O Papel do Programa de Aquisição de alimentos - PAA - para o fortalecimento da agricultura familiar: o caso da Cooperativa da Agricultura Familiar Rural Integrada - COOPAFI - de Capanema, PR. Dissertação de mestrado, Universidade Tecnológica Federal do Paraná, Pato Branco, PR, Brasil.

Silva, A. R. P., Barbosa, M. J. S., \& Albuquerque, F. S. (2013). Sustentabilidade de empreendimentos econômicos solidários: análise da Cooperativa dos Fruticultores de Abaetetuba. Revista de Administração Pública, 47(5), 1189-1212.

Silva, R. A., \& Torres, M. B. R. (2020). Sustentabilidade e educação ambiental na agricultura familiar: o caso de uma cooperativa no semiárido potiguar. Desenvolvimento e Meio Ambiente, 55, 300-313.

Ssebunya, B. R., Schader, C., Baumgart, L., Landert, J., Altenbuchner, C., Schmid, E., \& Stolze, M. (2019). Sustainability Performance of Certified and Non-certified Smallholder Coffee Farms in Uganda. Ecological Economics, 156, 35-47.

Strahl, D. A. (2019). Sustentabilidade social: a percepção dos cooperados de uma cooperativa agrícola do Rio Grande do Sul - Brasil. Dissertação de mestrado, Universidade Federal de Santa Maria, Santa Maria, RS, Brasil.

Tenzin, G., \& Natsuda, K. (2016). Social capital, household income, and community development in Bhutan: a case study of a dairy cooperative. Development in Practice, 26(4), 467-480. 
Ternoski, S. (2013). Estratégias de melhoria da renda da agricultura familiar: análise a partir da base social da CRESOL/Prudentópolis. Dissertação de mestrado, Universidade Tecnológica Federal do Paraná, Pato Branco, PR, Brasil.

Tilman, D., Cassman, K. G., Matson, P. A., Naylor, R., \& Polasky, S. (2002). Agricultural sustainability and intensive production practices. Nature, 418(6898), 671.

Tokarski, M. (2013). Desenvolvimento local: um estudo descritivo sobre a formação da COOPERFAP, uma cooperativa voltada ao desenvolvimento da agricultura familiar no município de Bela Vista do Toldo - SC. Dissertação de mestrado, Universidade do Contestado, Canoinhas, SC, Brasil.

Valandro, K. (2014). O papel do Programa Nacional de Alimentação escolar - PNAE para inserção da agricultura familiar em novos mercados: o caso da COOPAFI - Capanema. Dissertação de mestrado, Universidade Tecnológica Federal do Paraná, Pato Branco, PR, Brasil.

Vendrame, A. L. (2014). Cooperativismo, Agricultura Familiar e a adequação das propriedades rurais ao modelo de Produção Agroindustrial em Palotina - PR. Dissertação de mestrado, Universidade Estadual do Oeste do Paraná, Toledo, PR, Brasil.

Werbach, A. (2010). Estratégia para a sustentabilidade: uma nova forma de planejar sua estratégia empresarial. Rio de Janeiro: Elsevier.

Winck, C. A., Zonin, V. J., Scarton, L. M., \& Silva, T. N. (2014). Agricultura familiar e rendas alternativas na região da Quarta Colônia/RS. Revista Brasileira de Gestão e Desenvolvimento Regional, 10(1).

Xavier, M. L. B. (2013). Avaliação do resultado do Programa de Aquisição de Alimentos junto cooperativas de agricultores familiares de Santa Catarina. Dissertação de mestrado, Universidade do Estado Santa Catarina, Florianópolis, SC, Brasil.

Zanella, T. P., \& Lago, S. M. S. (2017). A produção científica brasileira sobre a sustentabilidade no agronegócio: um recorte temporal entre 2005 e 2015. Organizações Rurais \& Agroindustriais, 18(4), 356-370. 